\title{
Nanomaterial enabled sensors for environmental contaminants
}

\author{
Marjorie R. Willner and Peter J. Vikesland ${ }^{*}$
}

\begin{abstract}
The need and desire to understand the environment, especially the quality of one's local water and air, has continued to expand with the emergence of the digital age. The bottleneck in understanding the environment has switched from being able to store all of the data collected to collecting enough data on a broad range of contaminants of environmental concern. Nanomaterial enabled sensors represent a suite of technologies developed over the last 15 years for the highly specific and sensitive detection of environmental contaminants. With the promise of facile, low cost, field-deployable technology, the ability to quantitatively understand nature in a systematic way will soon be a reality. In this review, we first introduce nanosensor design before exploring the application of nanosensors for the detection of three classes of environmental contaminants: pesticides, heavy metals, and pathogens.
\end{abstract}

Keywords: Nanomaterials, Sensor, Detection, Environment, Pesticides, Heavy metals, Pathogens

\section{Background}

Nanomaterial enabled sensors are an exciting technology that provide exquisite detection, on the nanomolar to sub-picomolar level, of environmental contaminants [1-5]. Interest in these sensors stems from their potential for facile, in-field contaminant detection without the need for expensive lab equipment. Many past reviews in this area have grouped sensors based on the signal transduction method [2-5], nanoparticle backbone [7-10], or contaminant class $[1,11,12]$, thus leaving one important paradigm virtually untouched: classifying sensors based on the analyte(s) of interest. Because environmental scientists and engineers are often interested in determining if a specific contaminant exists at a field site and if its concentration is above the regulatory limit, there was a need to organize a review based upon the detection of specific contaminants. This review has been developed to address these concerns. First, we summarize the general concepts underlying a nano-enabled sensor and then discuss recent developments in nanomaterial enabled detection of nine specific analytes: two pesticides, four

\footnotetext{
*Correspondence: pvikes@vt.edu

Department of Civil and Environmental Engineering and the Institute

for Critical Technology and Applied Science, Center for Sustainable
}

Nanotechnology (VTSuN), Virginia Tech, Blacksburg, USA metals, and three pathogens. A nearly infinite number of chemicals of environmental concern exist and although it would be impossible to outline all of them, the fundamental nanosensor designs can be seen in the examples outlined within the review. For the reader interested in nanosensors for pharmaceutical detection we direct them to the work of Nagaraj et al. [13] and the reviews of Sanvicens et al. [14] and Cristea et al. on antibiotic detection [15].

\section{Introduction}

Nanomaterial enabled sensors consist of three components: a nanomaterial(s), a recognition element that provides specificity, and a signal transduction method that provides a means of relaying the presence of the analyte (Fig. 1). These components are not necessarily distinct entities within a sensor, but every nanosensor can be characterized on the basis of these three divisions. Sensors can be designed to detect a single analyte or multiple analytes, termed multiplex detection. In addition to detecting an analyte by producing a signal, a 'turn-on' or 'off/on' sensor, some of the sensors described below are based on a 'turn-off' or 'on/off' mechanism, where-by a decrease in signal indicates the presence of an analyte. 


\section{NANOSENSOR DESIGN}

\section{(i) Environmental Contaminants}

\begin{tabular}{|c|c|}
\hline \multicolumn{2}{|c|}{$\underline{\text { Pesticides }}$} \\
\hline Organochlorines & Carbamates* \\
\hline Pyrethroids & Neonicotinoids* \\
\hline $\begin{array}{c}\text { Phenoxy } \\
\text { Organophosphate }\end{array}$ & Atrazine* \\
\hline
\end{tabular}

$\frac{\text { Heavy Metals }}{\text { Lead* }}$
Mercury*
Cadmium*

Chromium *

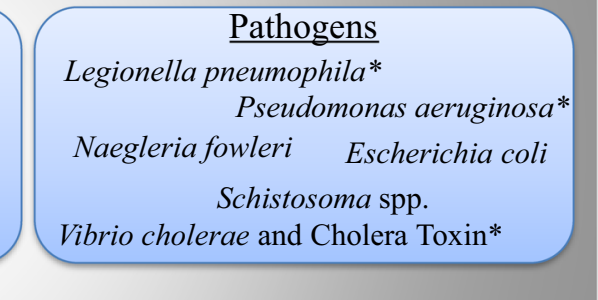

\section{$\downarrow$}

(ii) Number of Analytes Detected

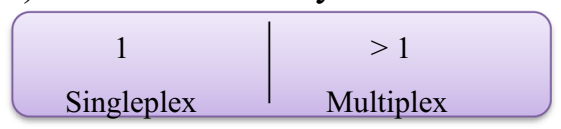

(iii) Nanoprobe Design

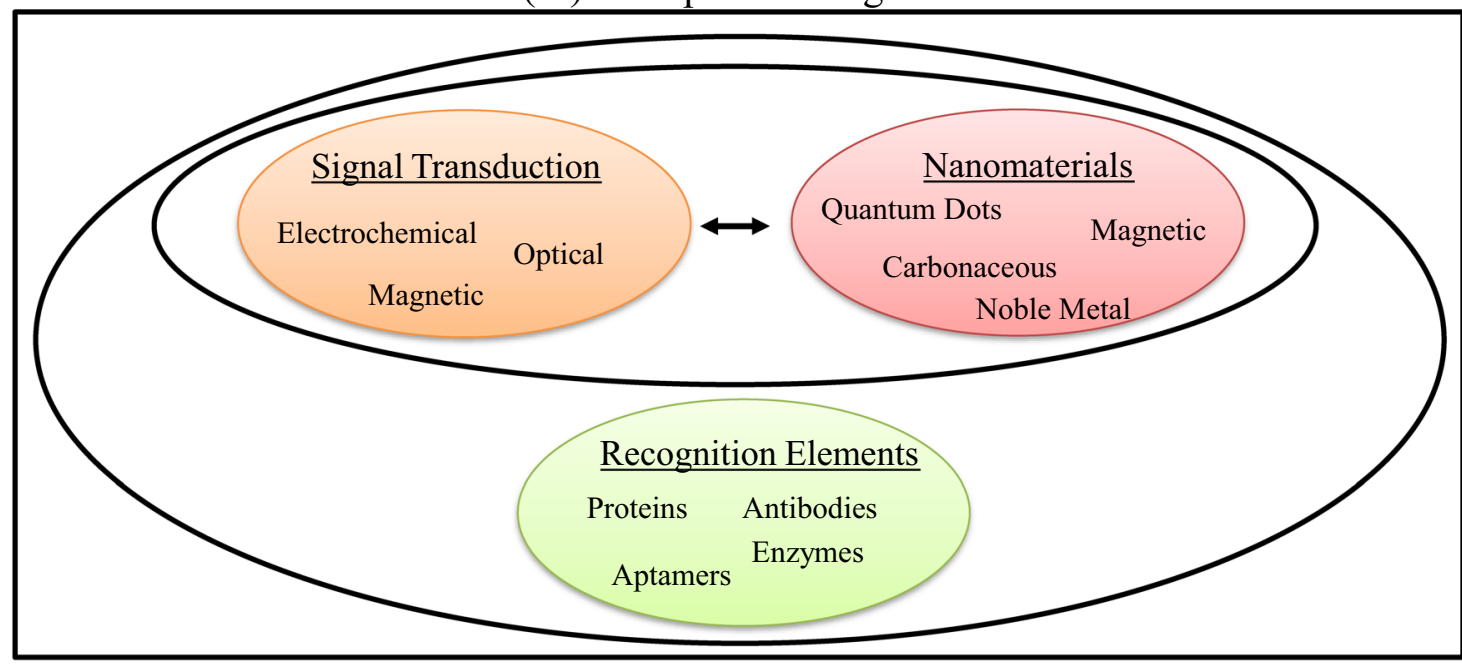

\section{$\downarrow$}

(iv) Sensor Deployment Format

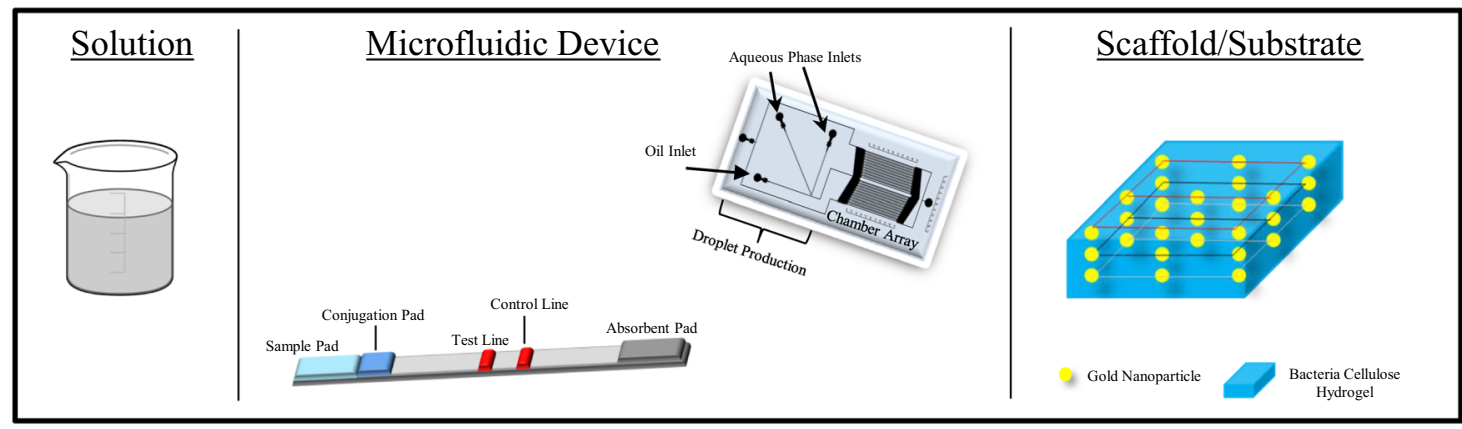

Fig. 1 Nanosensor design schematic. First, a class and subsequently a specific contaminant of interest is selected (i). The contaminants discussed in this review are denoted with an asterisk. Next, the number of analytes to be detected by the sensor is chosen (ii) and then the probe is designed. A nanoprobe consists of two core elements, a signal transduction method and at least one nanomaterial, and may also include a recognition element (iii). Ultimately, the sensor deployment format is selected (iv) 


\section{Nanomaterials}

Nanomaterials have enabled advances in sensor design such as miniaturization, portability, and rapid signal response times. High surface area to volume ratios and facile surface functionalization make nanomaterials highly sensitive to changes in surface chemistry thus enabling nanosensors to achieve extremely low detection limits. In some cases, the enhanced sensitivity of nanoenabled sensors is due to the fact that nanomaterials are of a similar size as the analyte of interest (e.g., metal ions, pathogens, biomolecules, antibodies, DNA) and are thus capable of interrogating previously unreachable matrices [4]. We briefly introduce three different general nanomaterial classes: quantum dots (QDs), metal nanoparticles, and carbonaceous nanomaterials.

\section{Quantum dots}

QDs are semiconductor nanocrystals with a typical composition $M X$ where $M$ is commonly cadmium (Cd) or zinc $(\mathrm{Zn})$ and $X$ is selenium (Se), sulfur $(\mathrm{S})$, or tellurium (Te). QDs are often coated by a second $M X$ alloy, a shell, to create core/shell QDs with highly tuned properties. Common QDs employed in sensor applications include: CdSe [16], CdSe/ZnS [17-19], CdTe [20-25], CdTe/CdS [22], ZnS [26], and ZnSe/ZnS [27]. QDs have characteristically narrow fluorescence emission bands, yet broad absorption bands, thus making them excellent optical transducers. Moreover, QD emission wavelengths can be readily adjusted by changing the size, shape or composition of the QD. Accordingly, QDs are ideal for multiplex detection of a number of different analytes. QDs diverse in shape, size, and composition can be excited by a single energy source because they have broad absorption spectra.

\section{Metal and metal oxide nanoparticles}

Because of their capacity to be produced in a wide variety of shapes, their high extinction coefficients $\left(\varepsilon>3 \times 10^{11} \mathrm{M}^{-1} \mathrm{~cm}^{-1}\right)$ [28], and their facile surface functionalization, noble metal nanoparticles (NP) have been extensively used in a number of sensor applications. Colloidal solutions of gold and silver nanoparticles, AuNP and AgNP respectively, exhibit unique colors based on the size of the colloidal nanomaterial. For example, AuNP spheres in the $\sim 5$ to $\sim 50 \mathrm{~nm}$ diameter range appear red in color but become more purple in hue as they increase in size towards $\sim 100 \mathrm{~nm}$. This color change can be exploited for use in visual colorimetric sensors where the presence of an analyte causes small nanoparticles to aggregate and the solution to change color. Gold and silver nanoparticle excitation can lead to the uniform oscillation of conduction electrons. This uniform oscillation gives rise to localized surface plasmon resonance (LSPR) [29] based spectroscopies such as surface plasmon resonance (SPR) and surface enhanced Raman spectroscopy (SERS). Plasmon based spectroscopies are discussed in greater detail below and elsewhere [28-30].

The chemistry of metal NPs, particularly AuNPs, has been exploited for use in highly selective sensors [31, 32]. We note that although it is possible to use AgNPs for sensor applications, the anti-microbial activity of silver [33] and its propensity to dissolve often limits the utility of such sensors. Gold NPs are stable, biocompatible, and have been extensively explored for use in sensing applications [7]. Surface coatings can be used to modify the particles and facilitate the attachment of recognition elements. Thiol capping agents provide colloidal stability and chemical functionality. Two commonly used thiols are thioglycolic acid (TGA) and 3-mercaptopropionic acid (MPA). These two agents impart a negative surface charge and create nanoparticles with an extremely high colloidal stability [34]. The choice of capping agent depends on the desired function and nanoparticle composition. The interested reader is referred to recent reviews by Saha et al. [7] and Wei et al. [35] for additional details on gold enabled sensors.

A range of nanostructured metal oxides (NMOs) have been explored for sensing applications. NMOs include: iron oxides, titanium oxides, zirconium oxides, cerium oxides, zinc oxides, and tin oxides. Magnetic iron oxides, such as magnetite $\left(\mathrm{Fe}_{3} \mathrm{O}_{4}\right)$ and maghemite $\left(\gamma-\mathrm{Fe}_{3} \mathrm{O}_{4}\right)$, have low toxicity, are economically friendly, and can be easily functionalized with ligands, antibodies, and other capping agents [36]. One important allure of magnetic NPs arises from their use in facilitated separation processes and remediation applications [12]. Titanium dioxide, $\mathrm{TiO}_{2}$, has also been embraced in nano-sensor design $[37,38]$, but it is most typically used and studied for its photocatalytic properties.

\section{Carbon-based nanomaterials}

Carbon nanotubes (CNTs) and graphene are often employed in nano-enabled sensors because of their large surface area, excellent electrical conductivity, high thermal conductivity and mechanical strength [39]. One recent application of these nanomaterials has been their use to increase the sensitivity of glassy carbon electrodes (GCE) for electrochemical sensing [40, 41]. Other sensor designs have exploited the electronic properties of graphene for fluorescence quenching. In such a design, as discussed later in this review, a QD with a recognition element is conjugated to a graphene sheet and in the presence of the analyte the sensor undergoes a conformational change that separates the QD from the graphene and "turns-on" the sensor. 


\section{Recognition elements}

Selectivity is an extremely important facet in the design of a successful biosensor. A diverse array of recognition elements have been implemented in nanosensor design including antibodies [42-46], aptamers [47-52], enzymes [53], and functional proteins [54]. The two most widely used agents, antibodies and aptamers, are described here in detail.

\section{Antibodies}

Antibodies (Abs) are proteins produced by the immune system in response to foreign agents [55]. They exhibit highly specific binding to a single antigen and are widely used in the capture and labeling of microorganisms and other materials that elicit an immune response [56]. Three types of antibodies have been used for analyte recognition: polyclonal (pAbs), monoclonal (mAbs), and engineered antibody fragments [57]. While antibodies are widely used in biosensors, there are a number of drawbacks to antibody use that include: high development costs, temperature and $\mathrm{pH}$ sensitivity, batch-tobatch variation, and short shelf-lives [44, 58]. Despite these disadvantages, for immunogenic analytes (i.e., those that elicit an immune response) Abs are often the most selective recognition agent [59]. Sensors that incorporate antibodies, either one type or multiple, are commonly referred to as immunosensors or immunoassays. A common descriptor of an electrochemical immunosensor is "label-free" because changes in the properties of the transducer surface owing to the antibody-antigen interaction can be directly measured [60].

\section{Aptamers}

Aptamers are flexible short oligonucleotide strands, either RNA or single stranded DNA (ssDNA), used to bind specific molecules. Produced both naturally and synthetically, aptamers have been designed to recognize toxic and non-immunogenic substances [61]. Aptamer production is estimated to cost approximately $10-50 \times$ less than antibody production [62]. Additionally, aptamers have low batch-to-batch variability, long shelf-lives, and are thermally stable [63]. Nucleic acid aptamers can be synthesized de novo with high specificity due either to the use of the systematic evolution of ligands by exponential enrichment (SELEX) process [64] or other newer isolation and synthesis approaches [65]. The SELEX process starts out by exposing a large library $\left(>10^{14}\right.$ strands) of random oligonucleotide sequences to the target sequence. Through affinity testing and polymerase chain reaction (PCR) amplification the oligonucleotide sequences with the tightest binding are isolated, their sequences determined, and following de novo synthesis can be incorporated into biosensors.

\section{Signal transduction}

The three major signal transduction methods employed in nano-enabled sensors are optical, electrochemical, and magnetic. Optical techniques, particularly colorimetric sensors that report a signal in the visible spectrum, are desirable for wide-scale use by the general public. A wellknown example of a colorimetric biosensor is the home pregnancy test. Electrochemical sensing methods have high specificity and can be simplistic and facile to miniaturize [2]. Compared with optical and electrochemical methods, magnetic transduction methods exhibit minimal background signal thus making them ideal for low concentration samples. Other sensor designs use magnetic materials to pre-concentrate the analyte prior to use of an optical or electrochemical transduction method.

\section{Optical}

Optical transduction is based on the interaction of a sensing element with electromagnetic radiation. Analytical techniques monitor emission or absorption of a sample under irradiation by ultraviolet, visible, or infrared light [66]. Two common optical methods utilized in nanosensor design are fluorescence and surface plasmon resonance enabled spectroscopies.

Fluorescence spectroscopy is based upon measurement of the emission of a fluorophore as it returns to its ground state following excitation. Fluorescent nanosensor applications often employ QDs or dye-doped silicon or polymer nanoparticle probes because they are photostable and are generally more robust than traditional fluorescent dyes $[67,68]$. Designs are described by the change in the fluorescence signal upon interaction with an analyte of interest as either "turn-off" or "turn-on". Quenching or restoration of the fluorescence signal may be a result of a direct interaction between the analyte and the nanoparticle or a conformational change in the sensor.

Surface plasmon resonance enabled spectroscopies are an optical transduction technique based on the localized surface plasmon resonance (LSPR) of noble metal nanomaterials $[3,35]$. The LSPR band is sensitive to the mean interparticle distance and therefore can be used to observe changes from a dispersed to an aggregated system or vice versa. Commonly, the LSPR is used in conjugation with a secondary spectroscopy technique to create a surface enhanced spectroscopy: surface enhanced fluorescence (SEF) or surface enhanced Raman spectroscopy (SERS) [67].

\section{Electrochemical}

Electrochemical detection methods measure the change in current or potential that result from the interaction between an analyte and an electrode. A multitude of techniques have been used to observe these changes 
and include cyclic voltammetry, chronoamperometry, chronopotentiometry, impedance spectroscopy, and various field-effect transistor based methods [4]. Nanoenabled sensor designs can involve modification of the solid electrode (e.g., platinum, gold, silver, graphite) with nano-carbons (e.g., carbon nanotubes, graphene) or functionalization with recognition elements (e.g., antibodies, aptamers) [2].

Direct spatial contact between the nanoscale architecture of the electrode and the recognition element gives rise to large signal amplification and improved signal to noise ratios compared to traditional electrochemical techniques $[2,4,69]$. In addition to the electrode properties, the size and morphology of the analyte of interest has been shown to affect sensor function. Improved detection limits have been shown for smaller particles due to their higher diffusivity and lower steric hindrance [70].

\section{Magnetic}

Magnetic transduction has been embraced for detection in biological samples because of the low background magnetic signal [71] and the fact that magnetic nanoparticles (MNP) can be collected under an applied magnetic field regardless of the optical properties of the solution [67]. Often, the use of magnetic nanoparticles to concentrate, separate and purify the analyte of interest in the detection zone is termed magnetic transduction [71]. However, a secondary transduction method, such as electrochemical stripping, can often be employed and therefore use of the term magnetic transduction can be a misnomer.

Magnetic-relaxation switches that incorporate superparamagnetic iron oxide nanoparticles are a pure form of magnetic transduction. The principle underlying this detection mechanism is the clustering of individual nanomagnetic probes into larger assemblies following interaction with a target. Analyte binding results in the formation of NP clusters and enhanced dephasing of the spins of the surrounding water protons. The subsequent change in the spin-spin (T2) relaxation can be detected by magnetic resonance relaxometry $[9,72]$. Magnetic relaxation switches have been used to detect nucleic acids (DNA and mRNA), proteins [73] and viruses [74] among other targets.

\section{Analytes}

As defined at the outset of this review, a wide variety of different analytes can be detected by nanomaterial-based sensors. In this portion of the review, we focus explicitly on the applications of nanosensors towards detection of pesticides, metals, and pathogens.

\section{Pesticides}

There is great interest in detection of pesticides given their widespread use, their toxicity, and their proclivity for bioaccumulation. Currently, over 800 active ingredients, in 100 different substance classes are present in commercial pesticides [75]; we summarize the major pesticide classes in Table 1. Organophosphorus (OP), carbamates, neonicotinoids, and triazines are the dominant classes and to date have been the focus of nano-enabled pesticide detection. Liu et al. [75], Verma et al. [76], Aragay et al. [1], Evtugyn et al. [60] and Pang et al. [77], provide detailed reviews of pesticide detection techniques. In this section, a brief background on pesticide detection will be followed by a discussion of recent advances.

\section{Organophosphates}

Pesticides are often designed to impact a specific enzyme; many forms of pesticide detection are based on observing and monitoring this enzyme either directly or indirectly. Organophosphate and carbamate pesticides inhibit the production of acetylcholinesterase (AChE) an enzyme that catalyzes the hydrolysis of acetylcholine, a neurotransmitter $[78,79]$. The fundamental reaction is shown in Eq. 1.

$$
\text { acetycholine }+\mathrm{H}_{2} \mathrm{O} \stackrel{A C h E}{\rightarrow} \text { choline }+ \text { acetate. }
$$

A class of rapid and sensitive electrochemical sensors has been developed around the immobilization of $\mathrm{AChE}$ on a solid electrode surface [41,80-82]. The products of Eq. 1 are not electroactive, and thus to detect the inhibition of AChE an analogous reaction based on the hydrolysis of acetylthiocholine is typically used [83].

For example, Yang et al. [84] combined two different types of nanomaterials, reduced graphene oxide (rGO) and gold nanoparticles, to achieve a detection limit of $0.5 \mathrm{nM}$ for the model organophosphate paraoxon-ethyl (Fig. 2). Reduced graphene oxide sheets provide an increased surface area for AChE immobilization and were deposited with polypyrrole (PPy) to prevent aggregation. Gold nanoparticles $(\sim 20 \mathrm{~nm})$ were then electrodeposited onto the PPy-rGO surface to further increase both the surface area and the conductivity of the electrode. The final step was co-deposition of AChE and a silica matrix, $\left(\mathrm{NH}_{4}\right)_{2} \mathrm{SiF}_{6}$. The biocompatible silica matrix prevented the AChE from leaking out of the electrode and ensured that the enzymes maintained their bioactivity. The completed sensor was tested using cyclic voltammetry and AChE inhibition was defined based on the peak experimental current and control current.

Similarly, Yu et al. [85] used the large surface area of carbon nanotubes to create a sensitive 
Table 1 Common pesticide classes

\begin{tabular}{|c|c|c|c|}
\hline Class of chemical pesticides & Examples & Types & Effects \\
\hline Carbamates & Carbaryl, methomyl, propoxur, aldicarb & Fungicide, insecticide, acaricide & $\begin{array}{l}\text { Non-persistent, cholinesterase-inhibiting, } \\
\text { not very selective, toxic to birds and fish }\end{array}$ \\
\hline Neonicotinoids & $\begin{array}{l}\text { Acetamiprid, clothianidin, imidacloprid, } \\
\text { nitenpyram, nithiazine, thiacloprid, } \\
\text { thiamethoxam }\end{array}$ & Insecticide & $\begin{array}{l}\text { Water soluble, concern regarding persis- } \\
\text { tence and bioaccumulation }\end{array}$ \\
\hline Organochlorines & $\begin{array}{l}\text { Aldrin, chlordane, dieldrin, endrin, } \\
\text { heptachlor; lindane, methoxychlor; } \\
\text { toxaphene, hexachlorobenzene (HCB), } \\
\text { pentachlorophenol (PCP), DDT }\end{array}$ & Insecticide, acaricide, fungicide & $\begin{array}{l}\text { Persistent, bioaccumulative, affects the } \\
\text { ability to reproduce, develop, and to } \\
\text { withstand environmental stress by } \\
\text { depressing the nervous, endocrine and } \\
\text { immune systems }\end{array}$ \\
\hline Organophosphates & Schradan; parathion; malathion & Insecticide, acaricide & $\begin{array}{l}\text { Non-persistent, systemic (cholinesterase- } \\
\text { inhibiting), not very selective, toxic to } \\
\text { humans }\end{array}$ \\
\hline Phenoxy & 2,4-D and 2,4,5-T & Herbicide & $\begin{array}{l}\text { Selective effects on humans and mam- } \\
\text { mals are not well known } \\
\text { 2,4-D: potential to cause cancer in labora- } \\
\text { tory animals } \\
\text { 2,4,5-T: is the source of a toxic contami- } \\
\text { nant dioxin }\end{array}$ \\
\hline Pyrethroids & $\begin{array}{l}\text { Fenpropathrin, deltamethrin, cyperme- } \\
\text { thrin }\end{array}$ & Insecticide & $\begin{array}{l}\text { Target-specific -more selective than the } \\
\text { organophosphates or carbamates, } \\
\text { generally not acutely toxic to birds } \\
\text { or mammals but particularly toxic to } \\
\text { aquatic species }\end{array}$ \\
\hline Triazines & Atrazine, cyanazine, and simazine & Herbicides & $\begin{array}{l}\text { Persistent, binds to the plastoquinone- } \\
\text { binding protein in photosystem II, } \\
\text { endocrine disruptor in humans }\end{array}$ \\
\hline
\end{tabular}

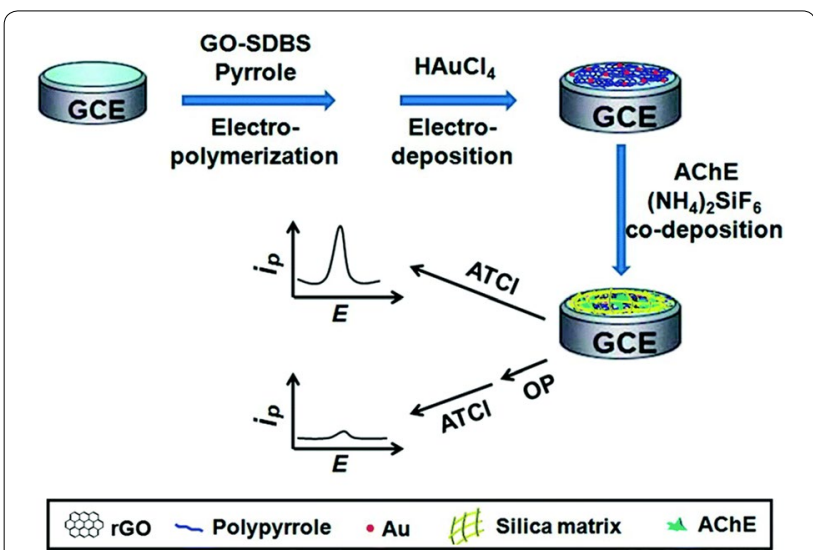

Fig. 2 Illustration of the preparation of the Au-PPy-rGO nanocomposite-based AChE biosensor. Illustration of the preparation of the Au-PPy-rGO nanocomposite-based AChE biosensor and its application for the electrochemical detection of organophosphorus pesticides (Reproduced from Yang et al. [84] with permission of The Royal Society of Chemistry)

organophosphorus pesticide (OP) biosensor. Amino functionalized carbon nanotubes $\left(\mathrm{CNT}-\mathrm{NH}_{2}\right)$ were dried on the surface of a standard glassy carbon electrode (GCE) and subsequently incubated with AChE.
Using differential pulse voltammetry (DPV), the limit of detection of the CNT decorated GCE was $0.08 \mathrm{nM}$.

Recently, Cui et al. [86] reported the use of a nanocomposite to improve the stability of $\mathrm{AChE}$ electrochemical biosensors. A layer of reduced graphene oxide (rGO) was introduced onto a glassy carbon electrode, followed by deposition of a titanium dioxide $\left(\mathrm{TiO}_{2}\right)$ porous sol-gel film mixed with chitosan (CS), a bio-compatible polymer. The stability of the matrix was further improved by the electro-deposition of a second layer of CS to yield a multi-layer mesoporous nanostructure. Total detection time required approximately $25 \mathrm{~min}$ and the limit of detection of dichlorvos, a model OP, was $29 \mathrm{nM}$. Although, the limit of detection of the sensor described in Yu et al. was better, without a side-to-side comparison of the sensors using the same test matrix no conclusion can be drawn with regard to sensor performance.

Pang et al. [87] explored the application of an aptamer SERS sensor in complex food samples. The assay utilized a unique aptamer developed by Zhang et al. [88] that can detect four distinct organophosphorous pesticides: phorate, profenofos, isocarbophos, and omethoate. Dendritic silver, an organized nanostructure, was selected as the SERS substrate because it provides locally consistent SERS enhancement factors [89]. The surface was decorated with aptamers and also a blocking agent, 
6-mercaptohexanol $(\mathrm{MH})$, to eliminate non-specific binding on the silver surface. Probes were incubated with the pesticides, removed from solution via centrifuge and dried prior to Raman interrogation. Analysis of each molecule's unique Raman fingerprint led to the determination of four distinct limits of detection: phorate $0.4 \mu \mathrm{M}$, isocarbophos $3.5 \mu \mathrm{M}$, omethoate $24 \mu \mathrm{M}$, and profenofos $14 \mu \mathrm{M}$.

Recently, Nie et al. [90] reported a similar SERSaptamer sensor, but with aqueous sample detection. Unlike Pang et al.s requirement to wash and drop-dry the probes onto a glass slide, Nie et al. mixed a malathion specific antibody with positively charged spermine coated silver nanoparticles and directly collected SERS spectra from the suspension. The phosphate backbone of the aptamer is negatively charged and electrostatic interactions led the aptamer complex to attach to the silver nanoprobes.

Fewer reports have described traditional optical immunoassays, such as the lateral flow immunoassay (LFIA), for OP detection. Wang et al. [91] developed a "bare-eye" assay with antibody functionalized gold nanoparticles that enabled the user to visually verify the presence or absence of three pesticides of interest: two OPs, chlorpyrifos-methyl and isocarbophos, and imidacloprid, a neonicotinoid. Of the three antibodies used, the antibody for isocarbophos (neonicotinoid) had to be developed inhouse because it had not previously been reported in the literature. In fact, antibodies exist for only about $~ 10 \%$ of the 800 active pesticide ingredients [75]. The production of a large library of pesticide antibodies has been stymied by the costs and difficulties in creating antibodies for these low molecular weight and non-rigid molecules [1].

\section{Neonicotinoids}

A class of neuro-active insecticides, neonicotinoids were first introduced in the 1980s and are currently the largest class of insecticides in use [92]. However, there are growing concerns regarding the impact of neonicotinoid to human health [93]. Nanosensors for neonicotinoid detection have focused specifically on the detection of acetamiprid with aptamers being the preferred recognition element as underscored by Verdian's recent review paper [94]. For example, Weerathunge et al. [95] exploited standard aptamer functionality to create a novel sensor based on the peroxidase-like activity of gold nanoparticles (GNP). As shown in Fig. 3, the colorless reporter molecule 3,3,5,5-tetramethylbenzidine (TMB), which turns purplish-blue upon oxidation, was used to create an off/on sensor with a signal observable via UV-visible absorbance. In the presence of an acetamiprid-specific aptamer, the oxidation of TMB is blocked. The introduction of the target molecule led to the desorption of

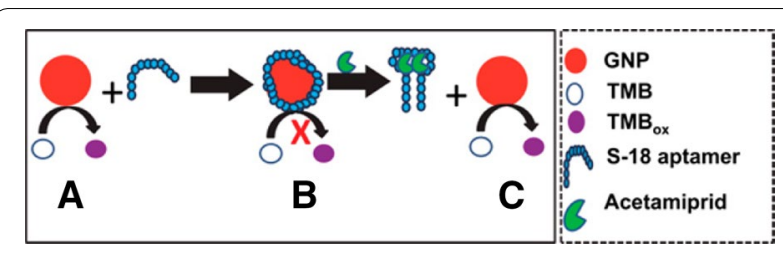

Fig. 3 Schematic representation of acetamiprid detection. Schematic representation of the reversible inhibition of the nanozyme activity of GNPs using an acetamiprid-specific S-18 ssDNA aptamer. Step A shows intrinsic peroxidase-like activity of GNPs that gets inhibited after shielding of the GNP surface through conjugation of S-18 aptamer molecules (step B). In the presence of acetamiprid target, the aptamer undergoes target-responsive structural changes and forms a supramolecular complex with acetamiprid resulting in free GNP to resume its peroxidase like activity (step C) (Reprinted with permission from Weerathunge et al. [95]. Copyright 2014 American Chemical Society)

the aptamer and restoration of TMB oxidation within $10 \mathrm{~min}$. The authors reported a limit of detection of $0.1 \mathrm{ppm}(450 \mathrm{nM})$ with a dynamic linear detection range of $0.1-10 \mathrm{ppm}$.

\section{Triazine}

A class of nitrogen heterocycles, triazine detection is typically limited to atrazine detection because it is one of the most comonly used herbicides in the United States [96]. A range of label-based [97, 98] and label-free [99-101] designs have been embraced for the detection of atrazine. For example, Liu et al. [97] designed a competitive electrochemical immunoassay. A gold electrode decorated with gold nanoparticles was functionalized with anti-atrazine monoclonal antibodies. Differential pulse voltammetry measurements were then used to directly measure changes in the electrode surface resulting from the antibody-antigen interaction. The sensor was determined to be highly sensitive with a limit of detection of $74 \mathrm{pM}$.

A unique label-free methods for atrazine detection was described by Wei and Vikesland [99]. A gold nanoparticle/bacteria cellulose (AuNP/BC) plasmonic nanocomposite was synthesized by the in situ reduction of gold salt in the presence of bacteria cellulose. As shown in Fig. 4, pH-triggered attachment of atrazine to the nanocomposite was achieved by lowering the $\mathrm{pH}$ of the solution below atrazine's $\mathrm{pK}_{\mathrm{a}}$ of 1.7 and was confirmed by an increase in the SERS signal in the AuNP/BC. Ultimately, the group was able to achieve a limit of detection of $11 \mathrm{nM}$, which is below the EPA's maximum concentration of $3 \mu \mathrm{g} / \mathrm{L}$ for drinking water, but three orders of magnitude greater than the label-based detection.

\section{Metals}

Nano-enabled sensors have been successfully developed for a number of heavy metals and in this section, we 


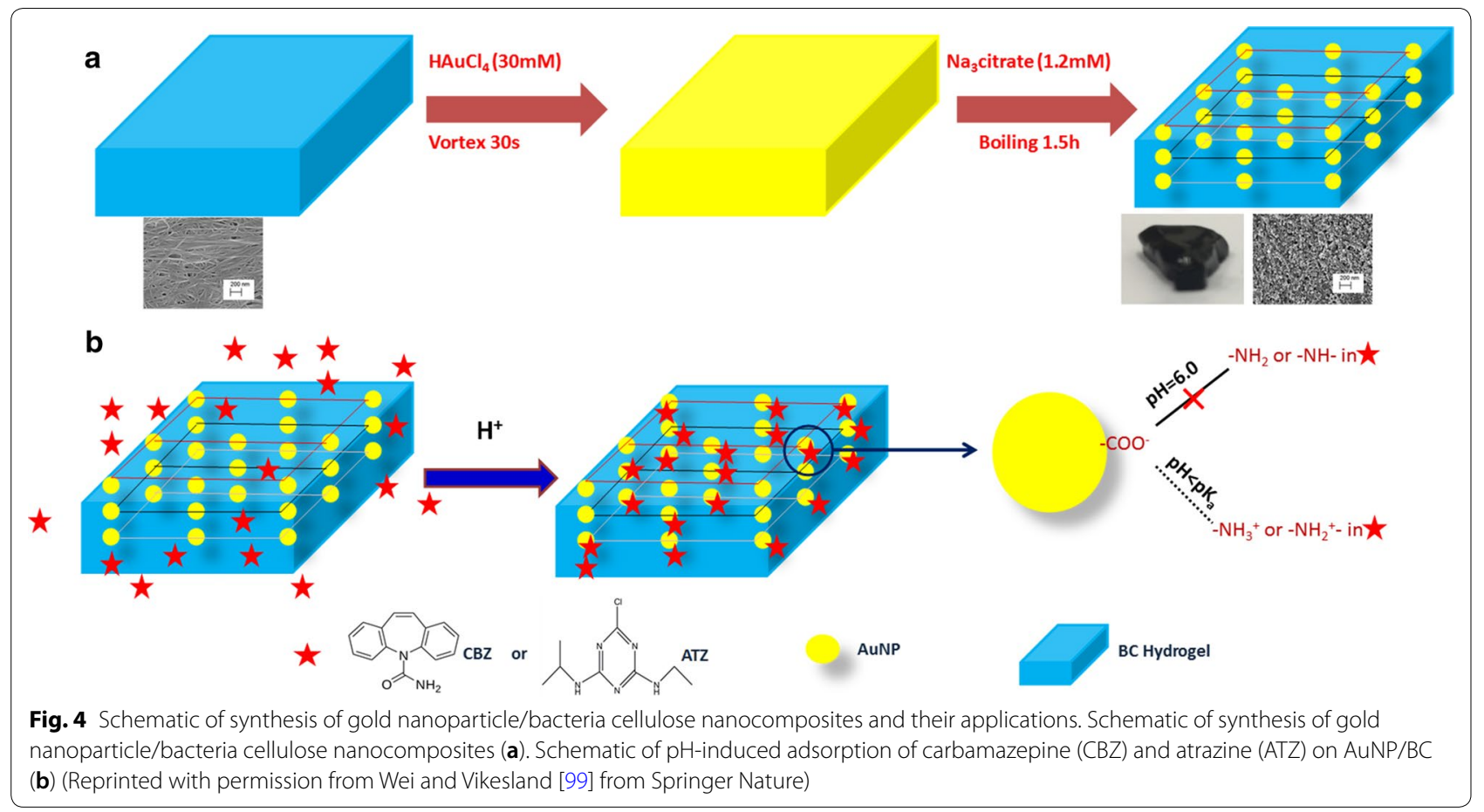

review mercury, lead, cadmium, and chromium detection. A diverse array of transducers and nanoparticles are used to detect these environmentally relevant contaminants all with the aim of developing sensitive and selective sensors. Readers interested in additional information about nanosensors for heavy metal detection are directed to the reviews of Li et al. [11] and Ullah et al. [102].

\section{Mercury}

The negative neurological effects of mercury exposure to humans have driven extensive investigation into the geochemical cycling and detection of this element [103]. A major focus of mercury $\left(\mathrm{Hg}^{\mathrm{II}}\right)$ nanosensor development has been the production of DNA-based probes [47-50, 104-106]. Thymine-thymine (T-T) base-mismatches in DNA are significantly stabilized in the presence of $\mathrm{Hg}^{\mathrm{II}}$ [104] due to the formation of metal base pairs [107]. Two major types of oligonucleotide mercury probes have been reported in the literature: G-quadruplexes $[48,49]$, which unfold, and nearly complementary single strands, which hybridize [106]. A growing number of mercury sensors are being constructed using multiple nano-elements, such as the mercury sandwich assay described by Liu et al. [50]. In this assay, magnetic silica spheres encapsulated in a gold shell and Raman labeled gold nanoparticles were functionalized with complementary DNA sequences that contained five mismatched thymine sites, Fig. 5. The DNA sequences were chosen such that the binding energy between the complementary

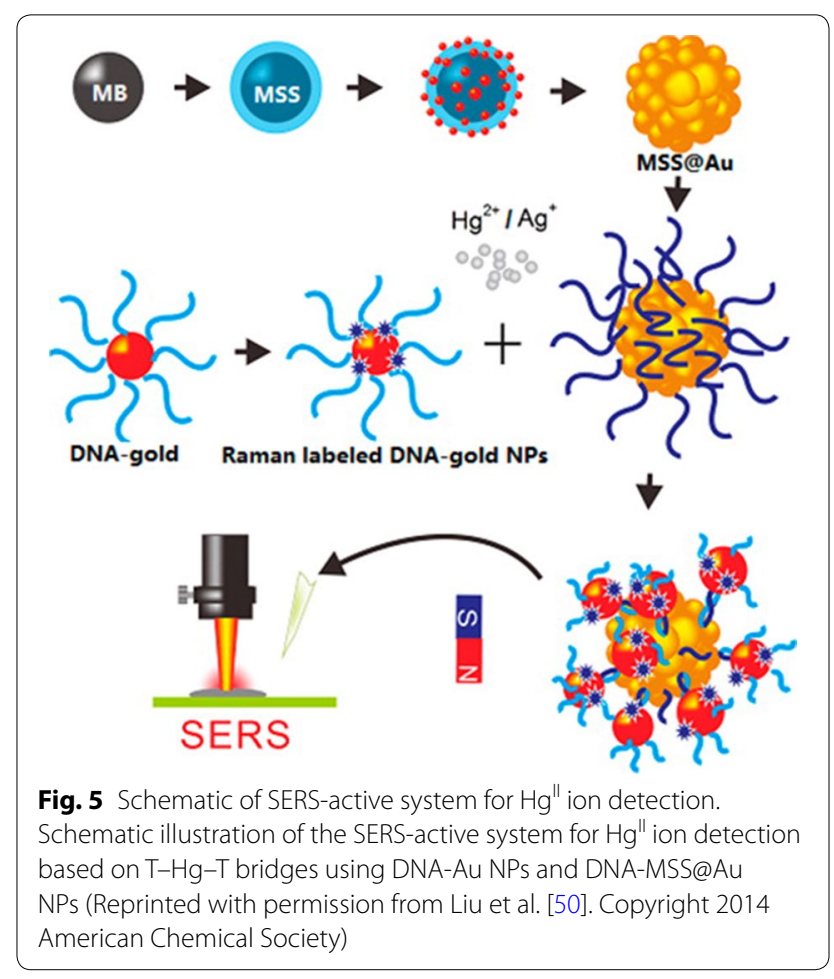

aspects of the strands was insufficient to allow them to fully hybridize. In the presence of mercury, full hybridization occurred thus decreasing the inter-probe spacing and creating a plasmonic hotspot. Owing to the magnetic 
particle cores, the nanoprobes could be easily recovered with an external magnet and subsequently recycled.

Thiol mediated assays for mercury detection have been described in the literature for a variety of nanoparticles such as gold [108-111], silver [112] or quantum dots [27]. Aggregation [108] or disaggregation [109] are typically utilized to provide a colorimetric response. Reaction based competition assays in which $\mathrm{Hg}^{\mathrm{II}}$ replaces a surface coating have also been described in the literature [32, 110]. Huang and Chang [110] created an on-sensor that emitted a fluorescence signal in the presence of mercury due to the displacement of rhodamine 6G (R6G) from the nanoparticle surface. In the process of iterating through three sensor designs to create a sensitive and selective assay, the authors found that thiol coatings increased the specificity of the assay for mercury. The final sensor was reported to have a limit of detection of $2.0 \mathrm{ppb}$ and a rapid analysis time $(<10 \mathrm{~min})$.

\section{Lead}

Associated with increased risk of cancer and subtle cognitive and neurological deficits [113], lead $(\mathrm{Pb})$ is a heavy metal contaminant of major concern. Labeled and labelfree nanosensors have both been reported for sensitive $\mathrm{Pb}^{\mathrm{II}}$ detection. For label-based detection, the recognition element 8-17 DNAzyme, a catalytic nucleic acid, has been used $[114,115]$ as well as a class of oligonucleotides that form G-quadruplexes in the presence of lead [17, 48, 116].

Tang et al. [115] combined 8-17 DNAzyme with rolling circle amplification (RCA) and quantum dots to develop an electrochemical sensor with a limit of detection of $7.8 \mathrm{pM}$. In this assay, DNAzyme catalytic strands were immobilized onto a magnetic bead (MB) and then hybridized with a substrate strand containing a single sessile ribonucleoside adenosine ( $\mathrm{rA}$ ) to form double stranded DNA with a single stranded loop to accommodate $\mathrm{Pb}^{\mathrm{II}}$ ion. In the presence of $\mathrm{Pb}^{\mathrm{II}}$, the DNAzyme was activated to cleave the substrate strand at the $\mathrm{rA}$ group. The exposed single DNA strand, tethered to the $\mathrm{MB}$, then hybridizes with the RCA template. Polymerase and deoxyribonucleotide triphosphates (dNTPs) were then added to trigger the RCA process and yield a long single stranded product with repeating sequence units. The complement of the RCA sequence was functionalized to CdS quantum dots leading to the hybridization of multiple QDs in a periodic arrangement. QD rich DNA duplexes were then magnetically separated from the solution and dissolved in nitric acid. The released cadmium cations were quantified via square wave voltammetry.

Gao et al. [117] developed an AlOOH-graphene oxide nanocomposite for the detection of lead and cadmium by square wave anodic stripping voltammetry (SWASV).
In this assay, the fast electron transfer kinetics achieved with graphene oxide were coupled to the high adsorption capacity of $\mathrm{AlOOH}$ to create a nanocomposite with a LOD of $76 \mathrm{pM}$. Unlike the RCA method, the AlOOH was not selective for a single metal. However, since each metal has a unique stripping peak the $\mathrm{AlOOH}$-graphene oxide nanocomposite could be used for multiplex detection.

\section{Cadmium}

The body of work on nano-enabled sensors for cadmium (Cd) detection is less robust than that for mercury and lead, but detection limits on the order of nano-molar have been reported. A variety of nanomaterials have been explored including QDs [22, 118], single wall carbon nanotubes (SWCNT) [119], and antimony nanoparticles [120].

Gui et al. [22] described an off/on-sensor fluorescence sensor for $\mathrm{Cd}^{\mathrm{II}}$ detection. Photoluminescent $\mathrm{CdTe} / \mathrm{CdS}$ QDs were first quenched (i.e., turned-off), by ammonium pyrrolidine dithiocarbamate (APDC) due to the partial loss of the $\mathrm{Cd}$-thiol surface layer and subsequent surface passivation. Introduced cadmium ions displaced the APDC from the QD surface and restored the photoluminescence (PL); thus, turning the sensor on. The sensor was highly selective for $\mathrm{Cd}^{\mathrm{II}}$, a threefold increase was seen in the PL intensity, and a limit of detection of $6 \mathrm{nM}$ was determined.

Gui et al. [118] enhanced the accuracy of their $\mathrm{Cd}^{\mathrm{II}}$ detection device by creating a ratiometric sensor. In this sensor, the fluorescence of two different chromophores was measured in order to minimize the error introduced by fluctuation in the photoluminescence of the QDs. To limit interactions between the QDs and the secondary dye, the CdTe QD cores were coated with a polymer, polyethylenimine (PEI), prior to conjugation with fluorescein isothiocyanate (FITC). The QDs were then quenched using sulfur $\left(\mathrm{S}^{2-}\right)$ while the FITC signal was maintained. Again, upon introduction of cadmium the sensor was turned on and the photoluminescence was restored. The limit of detection was slightly higher for this sensor compared to the same groups initial report, $12 \mathrm{nM}$ vs. $6 \mathrm{nM}$, but was linear across a much larger range, 0.1-15 $\mu \mathrm{M}$ compared with $0.1-2 \mu \mathrm{M}$.

\section{Chromium}

High chromium $(\mathrm{Cr})$ absorption in vivo can result in various diseases, including fibro-proliferative diseases, airway hypersensitivity, lung cancer, nasal cancer, and other types of tumors [121]. Multiple immunoassays have been described for the detection of chromium [45, 46], but they are all based on the work of Liu et al. [46]. In pursuit of an immunochromatographic assay (ICA), Liu et al. developed novel anti-CrIII-EDTA monoclonal 
antibodies (McAb). Chromium ions are too small to elicit an immune response and thus they were mixed with the highly effective bifunctional chelating agent, isothiocyanobenzyl-EDTA, and conjugated to the carrier protein bovine serum albumin (BSA) before being introduced to mice from which the antibodies were ultimately extracted. The immunoassay dipstick was composed of the three main parts: (i) a conjugation pad that was dosed with the anti-Cr-EDTA antibodies; (ii) a test line that contained the analyte of interest, Cr-EDTA, and; (iii) a control line that contained goat- anti-mouse antibodies. To run a sample, liquid is introduced to the dipstick and travels into the conjugation pad where the probes are brought into solution. For a negative sample, the free antibody probes bind to the test line, whereas in a positive sample no probes will bind as all antibody sites are already occupied and thus no signal is produced at the test line. The antibodies at the control line will capture any probes in the solution even those that are bound to the target of interest and is use to verify that capillary action wicked the solution through the whole length of the dipstick. The ultimate result of Liu et al. was an assay with a visual limit of detection of $50 \mathrm{ng} / \mathrm{mL}$ and an analysis time of $<5 \mathrm{~min}$.

\section{Pathogens}

Ever since John Snow's 1854 revelation that cholera was spread through the consumption of contaminated water, waterborne pathogen detection has been a key area of research. The World Health Organization (WHO) recognizes twelve bacteria, eight viruses, seven protozoa, and two helminths as pathogens of significance in drinking water supplies, as outlined in Table 2 [6]. Pathogen detection methods typically focus on: (i) whole analyte (cell) detection or detection of a representative epitope on the cell membrane; (ii) genetic material detection; or (iii) pathogenic product (e.g., toxin) detection. For the sake of brevity, herein we confine our discussion to the detection of Vibrio cholerae and the toxin it produces, cholera toxin, Legionella pneumophila, which was responsible for greater than $50 \%$ of the waterborne disease outbreaks between 2011 and 2012 [122], and Pseudomonas aeruginosa, which the WHO recently classified as a critical pathogen in light of the proliferation of antimicrobial resistant species [123]. For expanded reviews we refer the reader to the works of Kumar et al. [124] and Mocan et al. [125].

\section{Vibrio cholerae and cholera toxin}

Cholera, the infamous disease that spawned germ theory is now virtually unknown in the United States, but it continues to pose a major disease burden around the world with an estimated 1.3-4.0 million cases of cholera a year leading to between 21,000 and 143,000 deaths
Table 2 Waterborne pathogens and their significance in water supplies Adapted from WHO Table 7.1 waterborne pathogens and their significance in water supplies [6]

\begin{tabular}{|c|c|c|}
\hline Pathogen & Health significance & $\begin{array}{l}\text { Persistence } \\
\text { in water } \\
\text { supplies }\end{array}$ \\
\hline \multicolumn{3}{|l|}{ Bacteria } \\
\hline Burkholderia pseudomallei & High & May multiply \\
\hline Campylobacter jejuni, C. coli & High & Moderate \\
\hline Escherichia coli-pathogenic & High & Moderate \\
\hline E. coli-enterohaemorrhagic & High & Moderate \\
\hline Legionella spp. & High & May multiply \\
\hline Non-tuberculous mycobacteria & Low & May multiply \\
\hline Pseudomonas aeruginosa & Moderate & May multiply \\
\hline Salmonella typhi & High & Moderate \\
\hline Other salmonellae & High & May multiply \\
\hline Shigella spp. & High & Short \\
\hline Vibrio cholerae & High & Short to long \\
\hline Yersinia enterocolitica & Moderate & Long \\
\hline \multicolumn{3}{|l|}{ Viruses } \\
\hline Adenoviruses & Moderate & Long \\
\hline Enteroviruses & High & Long \\
\hline Astroviruses & Moderate & Long \\
\hline Hepatitis A virus & High & Long \\
\hline Hepatitis E virus & High & Long \\
\hline Noroviruses & High & Long \\
\hline Sapoviruses & High & Long \\
\hline Rotavirus & High & Long \\
\hline \multicolumn{3}{|l|}{ Protozoa } \\
\hline Acanthamoeba spp. & High & May multiply \\
\hline Cryptosporidium parvum & High & Long \\
\hline Cyclospora cayetanensis & High & Long \\
\hline Entamoeba histolytica & High & Moderate \\
\hline Giardia intestinalis & High & Moderate \\
\hline Naegleria fowleri & High & May multiply \\
\hline Toxoplasma gondii & High & Long \\
\hline \multicolumn{3}{|l|}{ Helminths } \\
\hline Dracunculus medinensis & High & Moderate \\
\hline Schistosoma spp. & High & Short \\
\hline
\end{tabular}

[126]. Cholera is an acute diarrhoeal disease caused by the ingestion of contaminated water or food containing the bacterium Vibrio cholerae. In the intestines, the bacteria colonize the mucosa and begin to secrete cholera toxin $(\mathrm{CT})$, which initiates the disease symptoms [127]. Nanosensors have been fabricated to detect both Vibrio cholerae $[128,129]$ and $\mathrm{CT}$, but the majority of the literature has focused on detection of CT subunit B (CT-B) [130-134] because the subunit induces cellular uptake of the toxin and not all $V$. cholerae isolates are toxigenic [135]. Label-based detection of CT can be achieved using antibodies, ganglioside GM1 (the binding site of CT), or 
$\beta$-galactose, a sugar with strong affinity towards CT. Ahn et al. [130] provide a nice summary of CT-B detection and reported a fluorescence resonance energy transfer (FRET) based method with a theoretical detection limit of 280 pM. In FRET, fluorescence from QDs is quenched, and the energy is transferred by another particle such as a gold nanoparticle. The quenching is inhibited in the presence of the target. Specifically, the cholera toxin binds to the $\beta$-galactose modified gold nanoparticles prohibiting the binding of the QDs.

\section{Legionella pneumophila}

Named for the famous 1976 outbreak at the American Legion, Legionnaires' disease is a pneumonia like disease caused by the bacterium Legionella pneumophila. Under specific conditions, the bacterium can flourish in building (premise) plumping and infect people when they inhale aerosols containing the infective agent. Two approaches have been presented in the literature for nano-enabled Legionella detection: whole organism detection [136, 137] and DNA detection [138-140].

Martin el al. [136] developed a whole organism sensor that combined a sandwich immunoassay for bacterial capture with amperometric transduction. Magnetic nanoparticles were modified with poly(dopamine) (pDA) and ultimately functionalized with specific capture antibodies (C-Ab) to create MNPs@pDA-C-Ab probes. After incubation with the sample, a second detector antibody labeled with horseradish peroxidase was introduced and a magnetic field was used to capture the immunocomplexes on a screen-printed carbon electrode (SPCE). The authors found the assay to be specific for Legionella, but they needed a preconcentration step in order to achieve a LOD below the reference of 100 colony-forming units (CFU) $\mathrm{L}^{-1}$. However, with a runtime of $<3 \mathrm{~h}$, compared to 10 days for the standard approach, and a LOD of $10 \mathrm{CFU} \mathrm{mL} \mathrm{m}^{-1}$, the sensor has the potential to be used as a rapid first screening method for highly contaminated water systems.

In a recent report, Melaine et al. [139] described the multiplex detection of $16 \mathrm{~S}$ rRNA from Legionella, Pseudomonas aeruginosa (discussed below) and Salmonella typhimurium. A DNA microarray with capture DNA specific for each target was assembled on a surface plasmon resonance imaging (SPRi) substrate, e.g., gold coated nanoprisms. Upon hybridization of the DNA with isolated 16S rRNA a change in the reflectivity signal was observed, as shown in the bottom of Fig. 6. To extend the dynamic range of detection and enhance sensitivity, gold nanoparticles functionalized with a detection probe were introduced to the sample and ultimately RNA at concentrations as low as $10 \mathrm{pg} \mathrm{mL}^{-1}$ were detected.

\section{Pseudomonas aeruginosa}

An opportunistic pathogen, Pseudomonas aeruginosa can be found in sources such as feces, soil, water, and sewage with the most important route of exposure being skin (dermal) contact with contaminated water or tools. Similar to Legionella, P. aeruginosa can colonize premise plumbing and has been associated with outbreaks of nosocomial infections in hospitals [141]. Most of the detection schemes reported for $P$. aeruginosa focus on whole pathogen detection [142-146] with the work of Melanie et al. [139], discussed above, on 16s rRNA detection being an outlier. In addition, to oligonucleotide recognition elements [139, 142-144], antibodies [145, 147] and bacteriophages [146] have also been used for specific detection of $P$. aeruginosa.

The first $P$. aeruginosa aptamer was discovered by Wang et al. [148] in 2011 and subsequently has been used in a range of sensors. The discussion that follows highlights two sensors that utilize optical transduction. Yoo et al. [142] and Hu et al. [144] fabricated nano-textured substrates to produce localized surface plasmon resonance (LSPR) chips (Fig. 7). Yoo et al. choose a three-step fabrication approach, first gold was deposited on a glass slide, silica nanoparticles were then deposited and then followed by the deposition of a second gold layer whereas $\mathrm{Hu}$ et al. opted for standard nanosphere lithography. The two groups also chose different methods to functionalize the sensor with Yoo et al. attaching the aptamers directly to the sensor surface via a gold-thiol bond. In contrast, $\mathrm{Hu}$ et al. used a polyethylene glycol (PEG) spacer to minimize steric hindrance for the aptamers with the goal of achieving a lower detection level. $\mathrm{Hu}$ et al. were successful at developing a sensor with a linear response at low concentrations and a lower limit of detection, $10 \mathrm{CFU} \mathrm{mL} \mathrm{m}^{-1}$ vs. Yoo et al's $10^{4} \mathrm{CFU} \mathrm{mL}^{-1}$. It should be noted that one of Yoo et al.s goals was to create a low volume sensor and that their LOD was obtained in a $3 \mu \mathrm{L}$ sample.

\section{Conclusions}

Nanosensor development for environmental contaminants is growing rapidly and, as described throughout this review, nanomaterials and recognition agents are continuously being combined in new and creative ways. The recent developments in sensor design aim to overcome the shortcomings of first-generation sensors such as nonspecific binding, particle size variation, nanoparticle aggregation, and nanoparticle stability. Questions of assay selectivity and sensitive in complex environmental matrices remains but a growing number of reports are using representative matrices to demonstrate the stability and selectivity of their sensors. The robustness of field 


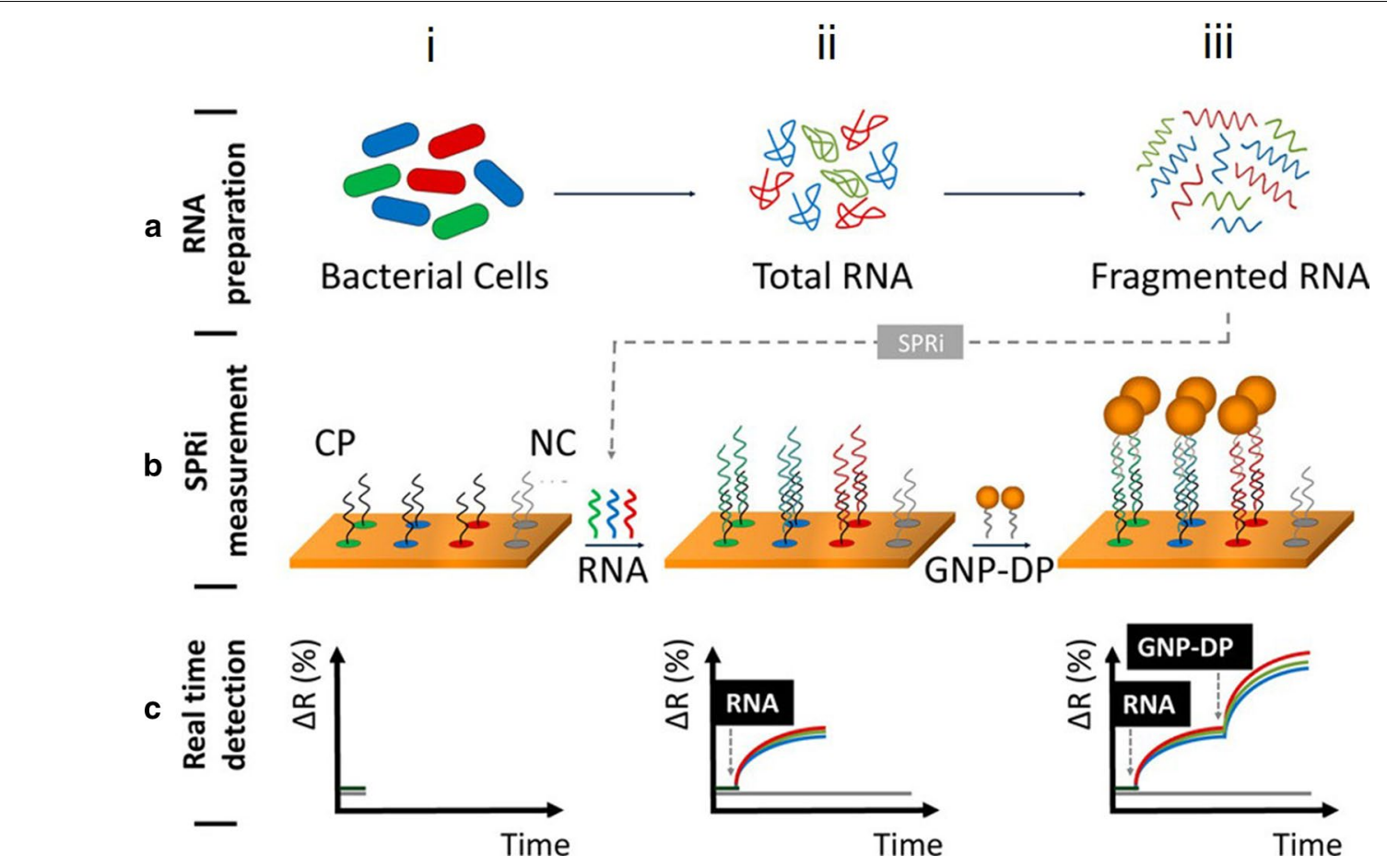

Fig. 6 A schematic of multiplex RNA detection using surface plasmon resonance imaging (SPRi). A schematic of multiplex RNA detection using surface plasmon resonance imaging (SPRi). RNA fragments are first extracted from bacteria of interest (a). A biochip functionalized with three specific capture probes (CP) and a negative control probe (NP), each demarcated in a unique color (b $(\mathrm{i})$ ) is shown to exhibit no change in reflectivity (c (i)). Upon introduction to the RNA (b (ii)), there is an increase in single (c (ii)). Finally, gold nanoparticles functionalized with the detection probe (GNP-DP) are introduced and shown to enhance the change in reflectivity (Adapted with permission from Melaine et al. [139]. Copyright 2017 American Chemical Society)
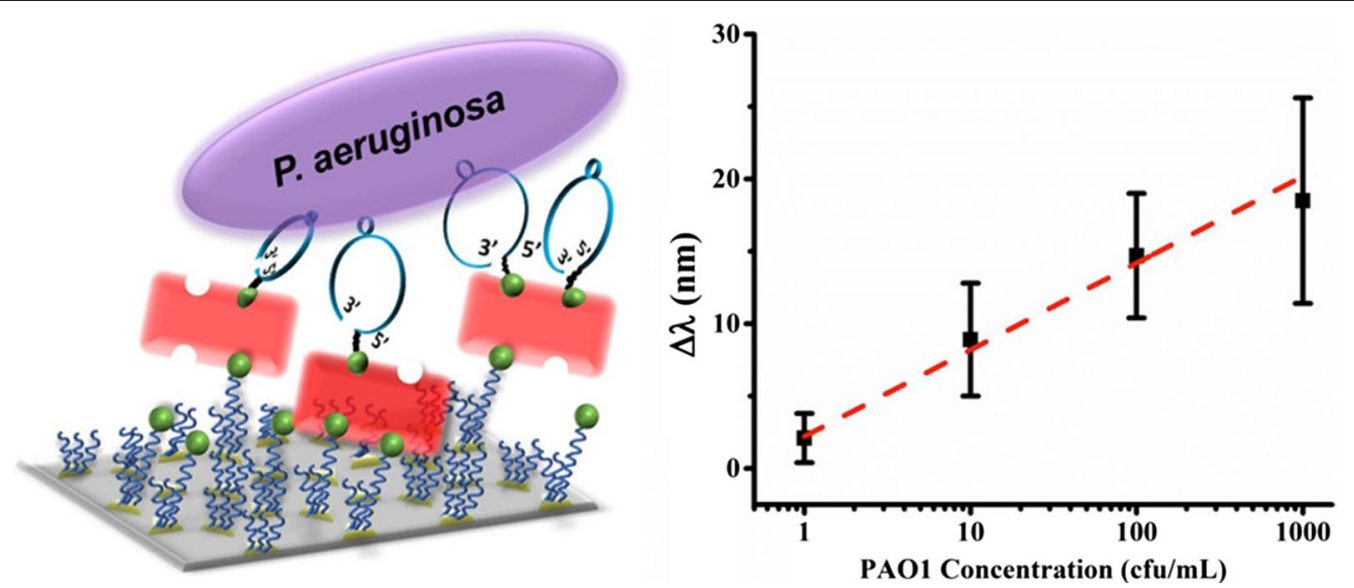

Fig. 7 Schematic of P. aeruginosa LSPR sensor chip (left). Sensor calibration curve, where error bar represents the standard deviation of all data points at a specific bacterial concentration (right). (Reprinted with permission from Hu et al. [144]. Copyright 2018 American Chemical Society) 


\section{deployable sensors is a must if individuals are going to be empowered to analyze their environment.}

\begin{abstract}
Abbreviations
Abs: antibodies; AChE: acetylcholinesterase; AgNP: silver nanoparticles; APDC: ammonium pyrrolidine dithiocarbamate; AuNP or GNP: gold nanoparticles; AuNP/BC: gold nanoparticle/bacteria cellulose; BSA: bovine serum albumin; Cd: cadmium; CFU: colony-forming unit; CNT: carbon nanotubes; $C$ r: chromium; CS: chitosan; CT: cholera toxin; DNA: deoxyribonucleic acid; dNTP: deoxyribonucleotide triphosphate; DPV: differential pulse voltammetry; $\mathrm{Fe}_{3} \mathrm{O}_{4}$ : magnetite; FRET: fluorescence resonance energy transfer; FTIC: fluorescein isothiocyanate; GCE: glassy carbon electrodes; Hg: mercury; ICA: immunochromatographic assay; LOD: fluorescence resonance energy transfer; LSPR: localized surface plasmon resonance; mAbs or McAb: monoclonal antibodies; MB: magnetic bead; MNP: magnetic nanoparticles; MPA: 3-mercaptopropionic acid; mRNA: messenger RNA; NMO: nanostructured metal oxides; NP: nanoparticles; OP: organophosphorus pesticide; pAbs: polyclonal; Pb: lead; PCR: polymerase chain reaction; PEG: polyethylene glycol; PEI: polyethylenimine; PL: photoluminescence; PPy: polypyrrole; QD: quantum dot; R6G: rhodamine 6G; rA: ribonucleoside adenosine; RCA: rolling circle amplification; rGO: reduced graphene oxide; RNA: ribonucleic acid; S: sulfur; Se: selenium; SEF: surface enhanced fluorescence; SELEX: systematic evolution of ligands by exponential enrichment; SERS: surface enhanced Raman spectroscopy; SPR: surface plasmon resonance; SPRi: surface plasmon resonance imaging; sSDNA: single stranded DNA; SWASV: square wave anodic stripping voltammetry; SWCNT: single wall carbon nanotubes; Te: tellurium; TGA: thioglycolic acid; $\mathrm{TiO}_{2}$ : titanium dioxide; TMB: 3,3,5,5-tetramethylbenzidine; WHO: World Health Organization; $\mathrm{Zn}$ : zinc; $\gamma-\mathrm{Fe}_{3} \mathrm{O}_{4}$ : maghemite.
\end{abstract}

\section{Authors' contributions}

MRW and PJV reviewed the literature. MRW drafted and wrote significant portions of the manuscript. MRW and PJV edited the manuscript. Both authors read and approved the final manuscript.

\section{Acknowledgements}

Support for MRW was provided by the Virginia Tech Graduate School through the Sustainable Nanotechnology Interdisciplinary Graduate Education Program (VTSUN IGEP).

\section{Competing interests}

The authors declare that they have no competing interests. The authors are entirely responsible for the content of the review of the opinions contained within it.

\section{Availability of data and materials \\ Not applicable.}

\section{Consent for publication}

Not applicable.

\section{Ethics approval and consent to participate}

Not applicable.

\section{Funding}

NSF and the Environmental Protection Agency under NSF Cooperative Agreement EF-0830093, Center for the Environmental Implications of NanoTechnology (CEINT).

\section{Publisher's Note}

Springer Nature remains neutral with regard to jurisdictional claims in published maps and institutional affiliations.

Received: 26 April 2018 Accepted: 7 November 2018

Published online: 22 November 2018

\section{References}

1. Aragay G, Pino F, Merkoci A. Nanomaterials for sensing and destroying pesticides. Chem Rev. 2012;112:5317-38.

2. Sadik $\mathrm{OA}$, Aluoch $\mathrm{AO}$, Zhou A. Status of biomolecular recognition using electrochemical techniques. Biosens Bioelectron. 2009:24:2749-65.

3. Bănică F-G. Nanomaterial applications in optical transduction. In: Chemical sensors and biosensors. Chichester: Wiley; 2012. p. 454-72.

4. Grieshaber D, MacKenzie R, Vörös J, Reimhult E. Electrochemical biosensors—sensor principles and architectures. Sensors. 2008;8:1400-58.

5. Liu G, Lin Y. Nanomaterial labels in electrochemical immunosensors and immunoassays. Talanta. 2007;74:308-17.

6. World Health Organization. Guidelines for drinking-water quality, vol. 1. Geneva: World Health Organization; 2008.

7. Saha K, Agasti SS, Kim C, Li X, Rotello VM. Gold nanoparticles in chemical and biological sensing. Chem Rev. 2012;112:2739-79.

8. Lu AH, Salabas EL, Schuth F. Magnetic nanoparticles: synthesis, protection, functionalization, and application. Angew Chem Int Ed Engl. 2007:46:1222-44.

9. Reddy LH, Arias JL, Nicolas J, Couvreur P. Magnetic nanoparticles: design and characterization, toxicity and biocompatibility, pharmaceutical and biomedical applications. Chem Rev. 2012;112:5818-78.

10. Xu Z, Dong J. Synthesis, characterization, and application of magnetic nanocomposites for the removal of heavy metals from industrial effluents. In: Shah V, editor. Emerging environmental technologies. Springer, Netherlands: Dordrecht; 2008. p. 105-48.

11. Li M, Gou H, Al-Ogaidi I, Wu N. Nanostructured sensors for detection of heavy metals: a review. ACS Sustain Chem Eng. 2013;1:713-23.

12. Mohmood I, Lopes C, Lopes I, Ahmad I, Duarte A, Pereira E. Nanoscale materials and their use in water contaminants removal — a review. Environ Sci Pollut Res. 2013;20:1239-60.

13. Nagaraj VJ, Jacobs M, Vattipalli KM, Annam VP, Prasad S. Nanochannelbased electrochemical sensor for the detection of pharmaceutical contaminants in water. Environ Sci Process Impacts. 2014;16:135-40.

14. Sanvicens N, Mannelli I, Salvador JP, Valera E, Marco MP. Biosensors for pharmaceuticals based on novel technology. TrAC Trends Anal Chem. 2011;30:541-53.

15. Cristea C, Tertis M, Galatus R. Magnetic nanoparticles for antibiotics detection. Nanomaterials. 2017:7:119.

16. Algarra M, Campos BB, Alonso B, Miranda MS, Martínez ÁM, Casado CM, Esteves da Silva JCG. Thiolated DAB dendrimers and CdSe quantum dots nanocomposites for Cd(II) or Pb(II) sensing. Talanta. 2012;88:403-7.

17. Li M, Zhou X, Guo S, Wu N. Detection of lead(II) with a "turn-on" fluorescent biosensor based on energy transfer from CdSe/ZnS quantum dots to graphene oxide. Biosens Bioelectron. 2013;43:69-74.

18. Luan W, Yang H, Wan Z, Yuan B, Yu X, Tu S-T. Mercaptopropionic acid capped CdSe/ZnS quantum dots as fluorescence probe for lead(II). J Nanopart Res. 2012;14:1-8.

19. Sung T-W, Lo Y-L. Highly sensitive and selective sensor based on silicacoated $\mathrm{CdSe} / \mathrm{ZnS}$ nanoparticles for $\mathrm{Cu}^{2+}$ ion detection. Sens Actuators B Chem. 2012;165:119-25.

20. Chao MR, Chang YZ, Chen JL. Hydrophilic ionic liquid-passivated CdTe quantum dots for mercury ion detection. Biosens Bioelectron. 2013:42:397-402

21. Gan TT, Zhang YJ, Zhao NJ, Xiao X, Yin GF, Yu SH, Wang HB, Duan JB, Shi CY, Liu WQ. Hydrothermal synthetic mercaptopropionic acid stabled CdTe quantum dots as fluorescent probes for detection of $\mathrm{Ag}(+)$. Spectrochim Acta A Mol Biomol Spectrosc. 2012;99:62-8.

22. Gui R, An X, Su H, Shen W, Chen Z, Wang X. A near-infrared-emitting $\mathrm{CdTe} / \mathrm{CdS}$ core/shell quantum dots-based OFF-ON fluorescence sensor for highly selective and sensitive detection of $\mathrm{Cd}^{2+}$. Talanta. 2012;94:257-62.

23. Liu X-Q, Liu Q, Cao S-H, Cai W-P, Weng Y-H, Xie K-X, Li Y-Q. Directional surface plasmon-coupled emission of CdTe quantum dots and its application in $\mathrm{Hg}$ (II) sensing. Anal Methods. 2012;4:3956.

24. Wu H, Liang J, Han $\mathrm{H}$. A novel method for the determination of $\mathrm{Pb}^{2+}$ based on the quenching of the fluorescence of $\mathrm{CdTe}$ quantum dots. Microchim Acta. 2007;161:81-6.

25. Wang YQ, Liu Y, He XW, Li WY, Zhang YK. Highly sensitive synchronous fluorescence determination of mercury(II) based on the denatured ovalbumin coated CdTe QDs. Talanta. 2012;99:69-74. 
26. Koneswaran M, Narayanaswamy R. I-Cysteine-capped ZnS quantum dots based fluorescence sensor for $\mathrm{Cu}^{2+}$ ion. Sens Actuators B Chem. 2009;139:104-9.

27. Ke J, Li X, Shi Y, Zhao Q, Jiang X. A facile and highly sensitive probe for $\mathrm{Hg}(\mathrm{II})$ based on metal-induced aggregation of ZnSe/ZnS quantum dots. Nanoscale. 2012;4:4996-5001.

28. Link S, El-Sayed MA. Spectral properties and relaxation dynamics of surface plasmon electronic oscillations in gold and silver nanodots and nanorods. J Phys Chem B. 1999:103:8410-26.

29. Romo-Herrera JM, Alvarez-Puebla RA, Liz-Marzan LM. Controlled assembly of plasmonic colloidal nanoparticle clusters. Nanoscale. 2011:3:1304-15.

30. Sonntag MD, Klingsporn JM, Zrimsek AB, Sharma B, Ruvuna LK, Van Duyne RP. Molecular plasmonics for nanoscale spectroscopy. Chem Soc Rev. 2014;43:1230-47

31. Chen Y-Y, Chang H-T, Shiang Y-C, Hung Y-L, Chiang C-K, Huang C-C. Colorimetric assay for lead ions based on the leaching of gold nanoparticles. Anal Chem. 2009;81:9433-9.

32. Lee Y-F, Nan F-H, Chen M-J, Wu H-Y, Ho C-W, Chen Y-Y, Huang C-C. Detection and removal of mercury and lead ions by using gold nanoparticle-based gel membrane. Anal Methods. 2012;4:1709.

33. Lok C-N, Ho C-M, Chen R, He Q-Y, Yu W-Y, Sun H, Tam P-H, Chiu J-F, Che C-M. Silver nanoparticles: partial oxidation and antibacterial activities. J Biol Inorg Chem. 2007;12:527-34.

34. Daniel M-C, Astruc D. Gold nanoparticles: assembly, supramolecular chemistry, quantum-size-related properties, and applications toward biology, catalysis, and nanotechnology. Chem Rev. 2004;104:293-346.

35. Wei H, Abtahi SH, Vikesland PJ. LSPR-based colorimetric and SERS sensors for environmental analysis. Environ Sci. 2015;2(2):120-35.

36. Hnaiein M, Hassen WM, Abdelghani A, Fournier-Wirth C, Coste J, Bessueille F, Leonard D, Jaffrezic-Renault N. A conductometric immunosensor based on functionalized magnetite nanoparticles for $E$. coli detection. Electrochem Commun. 2008;10:1152-4.

37. Filanovsky B, Markovsky B, Bourenko T, Perkas N, Persky R, Gedanken A, Aurbach D. Carbon electrodes modified with $\mathrm{TiO} 2 /$ metal nanoparticles and their application for the detection of trinitrotoluene. Adv Func Mater. 2007;17:1487-92

38. Li H, Li J, Xu Q, Yang Z, Hu X. A derivative photoelectrochemical sensing platform for 4-nitrophenolate contained organophosphates pesticide based on carboxylated perylene sensitized nano- $\mathrm{TiO}_{2}$. Anal Chim Acta. 2013;766:47-52

39. Yang W, Ratinac KR, Ringer SP, Thordarson P, Gooding JJ, Braet F. Carbon nanomaterials in biosensors: should you use nanotubes or graphene? Angew Chem Int Ed Engl. 2010;49:2114-38.

40. Fan H, Li Y, Wu D, Ma H, Mao K, Fan D, Du B, Li H, Wei Q. Electrochemical bisphenol A sensor based on N-doped graphene sheets. Anal Chim Acta. 2012;711:24-8

41. Dong J, Fan X, Qiao F, Ai S, Xin H. A novel protocol for ultra-trace detection of pesticides: combined electrochemical reduction of Ellman's reagent with acetylcholinesterase inhibition. Anal Chim Acta. 2013;761:78-83.

42. Kim YA, Lee E-H, Kim K-O, Lee YT, Hammock BD, Lee H-S. Competitive immunochromatographic assay for the detection of the organophosphorus pesticide chlorpyrifos. Anal Chim Acta. 2011;693:106-13.

43. Zhao WW, Ma ZY, Yu PP, Dong XY, Xu JJ, Chen HY. Highly sensitive photoelectrochemical immunoassay with enhanced amplification using horseradish peroxidase induced biocatalytic precipitation on a CdS quantum dots multilayer electrode. Anal Chem. 2012:84:917-23.

44. Trilling AK, Beekwilder J, Zuilhof H. Antibody orientation on biosensor surfaces: a minireview. Analyst. 2013;138:1619-27.

45. Jiajie L, Hongwu L, Caifeng L, Qiangqiang F, Caihong H, Zhi L, Tianjiu J, Yong T. Silver nanoparticle enhanced Raman scattering-based lateral flow immunoassays for ultra-sensitive detection of the heavy metal chromium. Nanotechnology. 2014;25:495501.

46. Liu X, Xiang JJ, Tang Y, Zhang XL, Fu QQ, Zou JH, Lin Y. Colloidal gold nanoparticle probe-based immunochromatographic assay for the rapid detection of chromium ions in water and serum samples. Anal Chim Acta. 2012:745:99-105.

47. Li M, Wang Q, Shi X, Hornak LA, Wu N. Detection of mercury(II) by quantum dot/DNA/gold nanoparticle ensemble based nanosensor via nanometal surface energy transfer. Anal Chem. 2011;83:7061-5.
48. Li T, Li B, Wang E, Dong S. G-quadruplex-based DNAzyme for sensitive mercury detection with the naked eye. Chem Commun. 2009. https:// doi.org/10.1039/b903993g.

49. Long F, Zhu A, Shi H, Wang H, Liu J. Rapid on-site/in-situ detection of heavy metal ions in environmental water using a structure-switching DNA optical biosensor. Sci Rep. 2013;3:2308.

50. Liu M, Wang Z, Zong S, Chen H, Zhu D, Wu L, Hu G, Cui Y. SERS detection and removal of mercury(II)/silver(I) using oligonucleotide-functionalized core/shell magnetic silica Sphere@Au nanoparticles. ACS Appl Mater Interfaces. 2014;6:7371-9.

51. Ma J, Chen Y, Hou Z, Jiang W, Wang L. Selective and sensitive mercuric(II) ion detection based on quantum dots and nicking endonuclease assisted signal amplification. Biosens Bioelectron. 2013;43:84-7.

52. Zhang M, Yin BC, Tan W, Ye BC. A versatile graphene-based fluorescence "on/off" switch for multiplex detection of various targets. Biosens Bioelectron. 2011;26:3260-5.

53. Evtugyn GA, Budnikov HC, Nikolskaya EB. Sensitivity and selectivity of electrochemical enzyme sensors for inhibitor determination. Talanta. 1998;46:465-84

54. Bies C, Lehr CM, Woodley JF. Lectin-mediated drug targeting: history and applications. Adv Drug Deliv Rev. 2004;56:425-35.

55. Rhoades RA, Pflanzer RG. Human physiology. Boston: Thomson Learning; 2002.

56. Ellington AA, Kullo IJ, Bailey KR, Klee GG. Antibody-based protein multiplex platforms: technical and operational challenges. Clin Chem. 2010;56:186-93.

57. Engvall E, Perlmann P. Enzyme-linked immunosorbent assay, Elisa. III quantitation of specific antibodies by enzyme-labeled anti-immunoglobulin in antigen-coated tubes. J Immunol. 1972;109:129-35.

58. Bordeaux J, Welsh AW, Agarwal S, Killiam E, Baquero MT, Hanna JA, Anagnostou VK, Rimm DL. Antibody validation. Biotechniques. 2010;48:197-209.

59. Huang CC, Huang YF, Cao Z, Tan W, Chang HT. Aptamer-modified gold nanoparticles for colorimetric determination of platelet-derived growth factors and their receptors. Anal Chem. 2005:77:5735-41.

60. Evtugyn GA. Biosensors for pesticides and foodborne pathogens. Portable biosensing of food toxicants and environmental pollutants., Sensors seriesBoca Raton: CRC Press; 2013. p. 605-80.

61. Famulok M, Mayer G. Aptamer modules as sensors and detectors. Acc Chem Res. 2011;44:1349-58.

62. Low SY, Hill JE, Peccia J. DNA aptamers bind specifically and selectively to $(1 \rightarrow 3)-\beta-d-g l u c a n s$. Biochem Biophys Res Commun. 2009;378:701-5.

63. Hamula CLA, Zhang H, Li F, Wang Z, Le Chris X, Li X-F. Selection and analytical applications of aptamers binding microbial pathogens. TrAC Trends Anal Chem. 2011;30:1587-97.

64. Stoltenburg R, Reinemann C, Strehlitz B. SELEX - a (r)evolutionary method to generate high-affinity nucleic acid ligands. Biomol Eng. 2007;24:381-403.

65. Hoinka J, Berezhnoy A, Dao P, Sauna ZE, Gilboa E, Przytycka TM. Large scale analysis of the mutational landscape in HT-SELEX improves aptamer discovery. Nucleic Acids Res. 2015:43:5699-707.

66. Bănică F-G. What are chemical sensors? In: Chemical sensors and biosensors. Chichester: Wiley; 2012. p. 1-20.

67. Vikesland PJ, Wigginton KR. Nanomaterial enabled biosensors for pathogen monitoring - a review. Environ Sci Technol. 2010;44:3656-69.

68. Bae SW, Tan W, Hong J-I. Fluorescent dye-doped silica nanoparticles: new tools for bioapplications. Chem Commun. 2012;48:2270-82.

69. Sanvicens N, Pastells C, Pascual N, Marco MP. Nanoparticle-based biosensors for detection of pathogenic bacteria. TrAC Trends Anal Chem. 2009:28:1243-52.

70. Garcia-Aljaro C, Cella LN, Shirale DJ, Park M, Munoz FJ, Yates MV, Mulchandani A. Carbon nanotubes-based chemiresistive biosensors for detection of microorganisms. Biosens Bioelectron. 2010;26:1437-41.

71. Koets $M$, van der Wijk T, van Eemeren JTWM, van Amerongen A, Prins MWJ. Rapid DNA multi-analyte immunoassay on a magneto-resistance biosensor. Biosens Bioelectron. 2009:24:1893-8.

72. Kaittanis C, Naser SA, Perez JM. One-step, nanoparticle-mediated bacterial detection with magnetic relaxation. Nano Lett. 2006;7:380-3.

73. Zhang Y, Yang Y, Ma W, Guo J, Lin Y, Wang C. Uniform magnetic core/ shell microspheres functionalized with $\mathrm{Ni}^{2+}$ _iminodiacetic acid for 
one step purification and immobilization of his-tagged enzymes. ACS Appl Mater Interfaces. 2013;5:2626-33.

74. Perez JM, Simeone FJ, Saeki Y, Josephson L, Weissleder R. Viral-induced self-assembly of magnetic nanoparticles allows the detection of viral particles in biological media. J Am Chem Soc. 2003;125:10192-3.

75. Liu S, Zheng Z, Li X. Advances in pesticide biosensors: current status, challenges, and future perspectives. Anal Bioanal Chem. 2013;405:63-90

76. Verma N, Bhardwaj A. Biosensor technology for pesticides—a review. Appl Biochem Biotechnol. 2015;175:3093-119.

77. Pang S, Yang T, He L. Review of surface enhanced Raman spectroscopic (SERS) detection of synthetic chemical pesticides. TrAC Trends Anal Chem. 2016;85:73-82.

78. Fukuto TR. Mechanism of action of organophosphorus and carbamate insecticides. Environ Health Perspect. 1990;87:245-54.

79. Stenersen J. Chemical pesticides mode of action and toxicology. Boca Raton: CRC Press; 2004.

80. Du D, Ye X, Cai J, Liu J, Zhang A. Acetylcholinesterase biosensor design based on carbon nanotube-encapsulated polypyrrole and polyaniline copolymer for amperometric detection of organophosphates. Biosens Bioelectron. 2010;25:2503-8.

81. Amine A, Mohammadi H, Bourais I, Palleschi G. Enzyme inhibitionbased biosensors for food safety and environmental monitoring. Biosens Bioelectron. 2006;21:1405-23.

82. Yadavalli VK, Koh W-G, Lazur GJ, Pishko MV. Microfabricated proteincontaining poly(ethylene glycol) hydrogel arrays for biosensing. Sens Actuators B Chem. 2004:97:290-7.

83. Nikolelis DP. Portable chemical sensors: weapons against bioterrorism. Dordrecht: Springer Netherlands; 2012

84. Yang Y, Asiri AM, Du D, Lin Y. Acetylcholinesterase biosensor based on a gold nanoparticle-polypyrrole-reduced graphene oxide nanocomposite modified electrode for the amperometric detection of organophosphorus pesticides. Analyst. 2014;139:3055-60.

85. Yu G, Wu W, Zhao Q, Wei X, Lu Q. Efficient immobilization of acetylcholinesterase onto amino functionalized carbon nanotubes for the fabrication of high sensitive organophosphorus pesticides biosensors. Biosens Bioelectron. 2015;68:288-94.

86. Cui H-F, Wu W-W, Li M-M, Song X, Lv Y, Zhang T-T. A highly stable acetylcholinesterase biosensor based on chitosan- $\mathrm{TiO}_{2}$-graphene nanocomposites for detection of organophosphate pesticides. Biosens Bioelectron. 2018:99:223-9.

87. Pang S, Labuza TP, He L. Development of a single aptamer-based surface enhanced Raman scattering method for rapid detection of multiple pesticides. Analyst. 2014;139:1895-901.

88. Zhang C, Wang L, Tu Z, Sun X, He Q, Lei Z, Xu C, Liu Y, Zhang X, Yang $J$, et al. Organophosphorus pesticides detection using broad-specific single-stranded DNA based fluorescence polarization aptamer assay. Biosens Bioelectron. 2014;55:216-9.

89. Laurier KGM, Poets M, Vermoortele F, Cremer GD, Martens JA, UjiH, De Vos DE, Hofkens J, Roeffaers MBJ. Photocatalytic growth of dendritic silver nanostructures as SERS substrates. Chem Commun. 2012;48:1559-61.

90. Nie Y, Teng Y, Li P, Liu W, Shi Q, Zhang Y. Label-free aptamer-based sensor for specific detection of malathion residues by surface-enhanced Raman scattering. Spectrochim Acta Part A Mol Biomol Spectrosc. 2018;191:271-6.

91. Wang LM, Cai J, Wang YL, Fang QK, Wang SY, Cheng Q, Du D, Lin YH, Liu FQ. A bare-eye-based lateral flow immunoassay based on the use of gold nanoparticles for simultaneous detection of three pesticides. Microchim Acta. 2014:181:1565-72.

92. Jeschke P, Nauen R, Schindler M, Elbert A. Overview of the status and global strategy for neonicotinoids. J Agric Food Chem. 2011;59:2897-908.

93. Simon-Delso N, Amaral-Rogers V, Belzunces LP, Bonmatin JM, Chagnon M, Downs C, Furlan L, Gibbons DW, Giorio C, Girolami V, et al. Systemic insecticides (neonicotinoids and fipronil): trends, uses, mode of action and metabolites. Environ Sci Pollut Res Int. 2015;22:5-34.

94. Verdian A. Apta-nanosensors for detection and quantitative determination of acetamiprid - a pesticide residue in food and environment. Talanta. 2018;176:456-64.
95. Weerathunge P, Ramanathan R, Shukla R, Sharma TK, Bansal V. Aptamercontrolled reversible inhibition of gold nanozyme activity for pesticide sensing. Anal Chem. 2014:86:11937-41.

96. United States Environmental Protection Agency (USEPA) Atrazine Chemical Summary 2007. https://archive.epa.gov/region5/teach/web/ pdf/atrazine_summary.pdf.

97. Liu X, Li W-J, Li L, Yang Y, Mao L-G, Peng Z. A label-free electrochemical immunosensor based on gold nanoparticles for direct detection of atrazine. Sens Actuators B Chem. 2014;191:408-14.

98. Yılmaz E, Özgür E, Bereli N, Türkmen D, Denizli A. Plastic antibody based surface plasmon resonance nanosensors for selective atrazine detection. Mater Sci Eng C. 2017;73:603-10.

99. Wei H, Vikesland PJ. pH-triggered molecular alignment for reproducible SERS detection via an AuNP/nanocellulose platform. Sci Rep. 2015:5:18131

100. Yang S, Wu T, Zhao X, Li X, Tan W. The optical property of core-shell nanosensors and detection of atrazine based on localized surface plasmon resonance (LSPR) sensing. Sensors. 2014:14:13273.

101. Mohapatra S, Bera MK, Das RK. Rapid "turn-on" detection of atrazine using highly luminescent $\mathrm{N}$-doped carbon quantum dot. Sens Actuators B Chem. 2018;263:459-68.

102. Ullah N, Mansha M, Khan I, Qurashi A. Nanomaterial-based optical chemical sensors for the detection of heavy metals in water: recent advances and challenges. TrAC Trends Anal Chem. 2018;100:155-66. https://doi.org/10.1016/j.trac.2018.01.002.

103. Selid $P, X u H$, Collins EM, Striped Face-Collins M, Zhao JX. Sensing mercury for biomedical and environmental monitoring. Sensors. 2009;9:5446-59.

104. Miyake Y, Togashi H, Tashiro M, Yamaguchi H, Oda S, Kudo M, Tanaka Y, Kondo Y, Sawa R, Fujimoto T, et al. Mercury"-mediated formation of thymine-Hg"-thymine base pairs in DNA duplexes. J Am Chem Soc. 2006;128:2172-3.

105. Gao ZF, Song WW, Luo HQ, Li NB. Detection of mercury ions (II) based on non-cross-linking aggregation of double-stranded DNA modified gold nanoparticles by resonance Rayleigh scattering method. Biosens Bioelectron. 2015:65:360-5.

106. Ono A, Togashi H. Highly selective oligonucleotide-based sensor for mercury(II) in aqueous solutions. Angew Chem Int Ed. 2004;43:4300-2.

107. Clever GH, Kaul C, Carell T. DNA-metal base pairs. Angew Chem Int Ed Engl. 2007:46:6226-36.

108. Kim Y-R, Mahajan RK, Kim JS, Kim H. Highly sensitive gold nanoparticlebased colorimetric sensing of mercury(II) through simple ligand exchange reaction in aqueous media. ACS Appl Mater Interfaces. 2009;2:292-5.

109. Xiaorong $Y$, Huixiang $L$, Juan $X$, Xuemei T, He H, Danbi T. A simple and cost-effective sensing strategy of mercury(II) based on analyteinhibited aggregation of gold nanoparticles. Nanotechnology. 2011;22:275503.

110. Huang CC, Chang HT. Selective gold-nanoparticle-based "turn-on" fluorescent sensors for detection of mercury(II) in aqueous solution. Anal Chem. 2006;78:8332-8

111. Chansuvarn W, Tuntulani T, Imyim A. Colorimetric detection of mercury(II) based on gold nanoparticles, fluorescent gold nanoclusters and other gold-based nanomaterials. TrAC Trends Anal Chem. 2015:65:83-96.

112. Alam A, Ravindran A, Chandran P, Sudheer Khan S. Highly selective colorimetric detection and estimation of $\mathrm{Hg}^{2+}$ at nano-molar concentration by silver nanoparticles in the presence of glutathione. Spectrochim Acta Part A Mol Biomol Spectrosc. 2015;137:503-8.

113. Goyer RA. Lead toxicity: from overt to subclinical to subtle health effects. Environ Health Perspect. 1990;86:177-81.

114. Kim H-K, Liu J, Li J, Nagraj N, Li M, Pavot CMB, Lu Y. Metal-dependent global folding and activity of the 8-17 DNAzyme studied by fluorescence resonance energy transfer. J Am Chem Soc. 2007:129:6896-902.

115. Tang S, Tong P, Li H, Tang J, Zhang L. Ultrasensitive electrochemical detection of $\mathrm{Pb}(2)(+)$ based on rolling circle amplification and quantum dots tagging. Biosens Bioelectron. 2013;42:608-11.

116. Li T, Wang E, Dong S. Lead(II)-induced allosteric G-quadruplex DNAzyme as a colorimetric and chemiluminescence sensor for highly sensitive and selective $\mathrm{Pb}^{2+}$ detection. Anal Chem. 2010;82:1515-20. 
117. Gao C, Yu XY, Xu RX, Liu JH, Huang XJ. AlOOH-reduced graphene oxide nanocomposites: one-pot hydrothermal synthesis and their enhanced electrochemical activity for heavy metal ions. ACS Appl Mater Interfaces. 2012;4:4672-82

118. Gui $R, A n X$, Huang W. An improved method for ratiometric fluorescence detection of $\mathrm{pH}$ and $\mathrm{Cd}^{2+}$ using fluorescein isothiocyanatequantum dots conjugates. Anal Chim Acta. 2013;767:134-40.

119. Sun D, Xie X, Cai Y, Zhang H, Wu K. Voltammetric determination of $\mathrm{Cd}^{2+}$ based on the bifunctionality of single-walled carbon nanotubes-Nafion film. Anal Chim Acta. 2007;581:27-31.

120. Toghill KE, Xiao L, Wildgoose GG, Compton RG. Electroanalytical determination of cadmium(II) and lead(II) using an antimony nanoparticle modified boron-doped diamond electrode. Electroanalysis. 2009;21:1113-8.

121. Gibb HJ, Lees PS, Pinsky PF, Rooney BC. Lung cancer among workers in chromium chemical production. Am J Ind Med. 2000;38:115-26.

122. Beer KD, Gargano JW, Roberts VA, Hill VR, Garrison LE, Kutty PK, Hilborn ED, Wade TJ, Fullerton KE, Yoder JS. Surveillance for waterborne disease outbreaks associated with drinking water-United States, 2011-2012. MMWR Morb Mortal Wkly Rep. 2015;64:842-8.

123. World Health Organization. WHO publishes list of bacteria for which new antibiotics are urgently needed. Geneva: WHO; 2017.

124. Kumar N, Hu Y, Singh S, Mizaikoff B. Emerging biosensor platforms for the assessment of water-borne pathogens. Analyst. 2018;143:359-73.

125. Mocan T, Matea CT, Pop T, Mosteanu O, Buzoianu AD, Puia C, lancu C, Mocan L. Development of nanoparticle-based optical sensors for pathogenic bacterial detection. J Nanobiotechnology. 2017;15:25.

126. Ali M, Nelson AR, Lopez AL, Sack DA. Updated global burden of cholera in endemic countries. PLoS Negl Trop Dis. 2015;9:e0003832.

127. Finkelstein RA. Cholera, Vibrio cholerae $\mathrm{O} 1$ and 0139 , and other pathogenic vibrios. In: Baron S, editor. Medical microbiology. 4th ed. Galveston: University of Texas Medical Branch at Galveston; 1996.

128. Yu CY, Ang GY, Chua AL, Tan EH, Lee SY, Falero-Diaz G, Otero O, Rodríguez I, Reyes F, Acosta A, et al. Dry-reagent gold nanoparticle-based lateral flow biosensor for the simultaneous detection of Vibrio cholerae serogroups $\mathrm{O} 1$ and O139. J Microbiol Methods. 2011;86:277-82.

129. Tam PD, Thang CX. Label-free electrochemical immunosensor based on cerium oxide nanowires for Vibrio cholerae $\mathrm{O} 1$ detection. Mater Sci Eng C. 2016:58:953-9.

130. Ahn K-S, Lim KR, Jeong D, Lee BY, Kim KS, Lee W-Y. Fluorescence energy transfer inhibition bioassay for cholera toxin based on galactosestabilized gold nanoparticles and amine-terminated quantum dots. Microchem J. 2016;124:9-14.

131. Khan SA, DeGrasse JA, Yakes BJ, Croley TR. Rapid and sensitive detection of cholera toxin using gold nanoparticle-based simple colorimetric and dynamic light scattering assay. Anal Chim Acta. 2015;892:167-74.

132. Zhang C-H, Liu L-W, Liang P, Tang L-J, Yu R-Q, Jiang J-H. Plasmon coupling enhanced raman scattering nanobeacon for single-step, ultrasensitive detection of cholera toxin. Anal Chem. 2016;88:7447-52.

133. Goldman ER, Clapp AR, Anderson GP, Uyeda HT, Mauro JM, Medintz IL, Mattoussi $H$. Multiplexed toxin analysis using four colors of quantum dot fluororeagents. Anal Chem. 2004;76:684-8.
134. Schofield CL, Field RA, Russell DA. Glyconanoparticles for the colorimetric detection of cholera toxin. Anal Chem. 2007;79:1356-61.

135. Azarian T, Ali A, Johnson JA, Jubair M, Cella E, Ciccozzi M, Nolan DJ, Farmerie W, Rashid MH, Sinha-Ray S, et al. Non-toxigenic environmental Vibrio cholerae $\mathrm{O} 1$ strain from Haiti provides evidence of pre-pandemic cholera in Hispaniola. Sci Rep. 2016;6:36115.

136. Martín M, Salazar P, Jiménez C, Lecuona M, Ramos MJ, Ode J, Alcoba J, Roche R, Villalonga R, Campuzano S, et al. Rapid Legionella pneumophila determination based on a disposable core-shell Fe $\mathrm{O}_{4} @$ poly(dopamine) magnetic nanoparticles immunoplatform. Anal Chim Acta. 2015;887:51-8.

137. Park J, You X, Jang Y, Nam Y, Kim MJ, Min NK, Pak JJ. ZnO nanorod matrix based electrochemical immunosensors for sensitivity enhanced detection of Legionella pneumophila. Sens Actuators B Chem. 2014;200:173-80.

138. Wu T-Y, Su Y-Y, Shu W-H, Mercado AT, Wang S-K, Hsu L-Y, Tsai Y-F, Chen C-Y. A novel sensitive pathogen detection system based on microbead quantum dot system. Biosens Bioelectron. 2016;78:37-44.

139. Melaine F, Saad M, Faucher S, Tabrizian M. Selective and high dynamic range assay format for multiplex detection of pathogenic Pseudomonas aeruginosa, Salmonella typhimurium, and Legionella pneumophila RNAs using surface plasmon resonance imaging. Anal Chem. 2017:89:7802-7.

140. Foudeh AM, Daoud JT, Faucher SP, Veres T, Tabrizian M. Sub-femtomole detection of $16 \mathrm{~s}$ rRNA from Legionella pneumophila using surface plasmon resonance imaging. Biosens Bioelectron. 2014;52:129-35.

141. Falkinham JO III, Hilborn ED, Arduino MJ, Pruden A, Edwards MA. Epidemiology and ecology of opportunistic premise plumbing pathogens: Legionella pneumophila, Mycobacterium avium, and Pseudomonas aeruginosa. Environ Health Perspect. 2015;123:749.

142. Yoo SM, Kim D-K, Lee SY. Aptamer-functionalized localized surface plasmon resonance sensor for the multiplexed detection of different bacterial species. Talanta. 2015;132:112-7.

143. Jia F, Xu L, Yan W, Wu W, Yu Q, Tian X, Dai R, Li X. A magnetic relaxation switch aptasensor for the rapid detection of Pseudomonas aeruginosa using superparamagnetic nanoparticles. Microchim Acta. 2017;184:1539-45.

144. Hu J, Fu K, Bohn PW. Whole-cell Pseudomonas aeruginosa localized surface plasmon resonance aptasensor. Anal Chem. 2018;90(3):2326-32.

145. Krithiga N, Viswanath KB, Vasantha VS, Jayachitra A. Specific and selective electrochemical immunoassay for Pseudomonas aeruginosa based on pectin-gold nano composite. Biosens Bioelectron. 2016;79:121-9.

146. He Y, Wang M, Fan E, Ouyang H, Yue H, Su X, Liao G, Wang L, Lu S, Fu $Z$. Highly specific bacteriophage-affinity strategy for rapid separation and sensitive detection of viable Pseudomonas aeruginosa. Anal Chem. 2017:89:1916-21.

147. Ellairaja S, Krithiga N, Ponmariappan S, Vasantha VS. Novel pyrimidine tagged silver nanoparticle based fluorescent immunoassay for the detection of Pseudomonas aeruginosa. J Agric Food Chem. 2017:65:1802-12.

148. Wang K-Y, Zeng Y-L, Yang X-Y, Li W-B, Lan X-P. Utility of aptamerfluorescence in situ hybridization for rapid detection of Pseudomonas aeruginosa. Eur J Clin Microbiol Infect Dis. 2011;30:273-8.

Ready to submit your research? Choose BMC and benefit from

- fast, convenient online submission

- thorough peer review by experienced researchers in your field

- rapid publication on acceptance

- support for research data, including large and complex data types

- gold Open Access which fosters wider collaboration and increased citations

- maximum visibility for your research: over 100M website views per year

At $\mathrm{BMC}$, research is always in progress.

Learn more biomedcentral.com/submissions 